\title{
Pattern of Injuries in Patients Visiting Emergency Department of Hawassa University Comprehensive Specialized Hospital, Hawassa, Ethiopia
}

\author{
Thomas Fako*, Mohammed Ayalew \\ School of Nursing, Faculty of Health Sciences, College of Medicine and Health sciences, Hawassa University, Hawassa, Ethiopia \\ Email address: \\ ettom@ymail.com (T. Fako), mameayale@gmail.com (M. Ayalew) \\ ${ }^{*}$ Corresponding author

\section{To cite this article:} \\ Thomas Fako, Mohammed Ayalew. Pattern of Injuries in Patients Visiting Emergency Department of Hawassa University Comprehensive \\ Specialized Hospital, Hawassa, Ethiopia. American Journal of Clinical and Experimental Medicine. Vol. 8, No. 2, 2020, pp. 15-19. \\ doi: $10.11648 /$ j.ajcem.20200802.12
}

Received: July 19, 2019; Accepted: August 13, 2019; Published: May 28, 2020

\begin{abstract}
Injuries are major public health problem globally. Each year over 5 million people around the world die as result of injury. Injuries are ranked among the leading cause of death and disability particularly in the low income and middle income countries where they are growing in significance. The general objective of this research was to assess pattern of injury among patients visiting the emergency department of Hawassa University Comprehensive Specialized Hospital, Hawassa, Ethiopia. Retrospective cross-sectional study was conducted among injured patients, who visited the adult Emergency Department of Hawassa University Comprehensive Specialized Hospital from February 2015 to June 2015. Data was collected using structured check list adopted from World Health Organization (WHO) Injury surveillance guideline with modification. Most injuries occurred by road traffic accident accounted for $54 \%$ and the majority $80 \%$ were male. The more injured age group was 21-30 and accounted for $41 \%$. Among the injuries, $62 \%$ of the injuries were accidental, anatomically injured part of the body was head and neck which was accounted for $52.2 \%$. This research is crucial and base line to understand the problems of injury and the policy maker will develop guide lines to prevent the cause of trauma and improving health care service systems in health institutions and society.
\end{abstract}

Keywords: Pattern, Injury, Emergency Department, Ethiopia

\section{Introduction}

Globally, injuries are considered to be the major public health problem. Over 5 million people die as result of injury each year around the world and nearly 2 times the number of fatalities that result from HIV/AIDS, tuberculosis and malaria combined [1]. Injuries are responsible for almost $10 \%$ of global burden of mortality, of which more than $90 \%$ of this burden falls upon those living in low income countries [2]. Globally, about 14,000 people lost their lives due to injury each day [1].

In the United States at least one person dies from an injury every 3 minutes [3]. Among the major causes of injury violence, road traffic crashes, burns, drowning, falls, and poisonings accounts the top rank [1]. In American, motor vehicle crashes, falls, or homicides cause more death than other causes below the age of 44 [4]. Physical and financial costs can be resulted from injuries, which affect the lives of individuals and their families. Furthermore, the treatment of injuries put an enormous burden on hospital emergency departments and trauma care systems [5]. Almost 48 percent of all injury-related emergency department visits in US accounted is accounted by patients younger than 30 years of age [6].

About $12 \%$ of hospital beds in United States of America and more than half of orthopedic admissions in the United Kingdom were occupied by injured patients [7]. Nearly two third $(60.7 \%)$ of the accident victims belonged to the age range of 15 to 44 years. This is the economically productive age-group and major financial support for their families [8]. Road traffic accidents (RTAs) are the leading cause of morbidity and mortality in adolescents and young adults 
globally and one of the top three causes of deaths for 5-44 years age group in many countries is RTIs [9]. It is estimated that by the year 2020, more than 8 million people will die every year from injury [10] and injuries from road traffic accidents will be the third most common cause of disability worldwide and the second most common cause in the developing world [11]. According to WHO global status report more than 1.25 million people die annually and 20-50 million sustaining non-fatal injuries occurred due to road traffic accidents in 2015 [12] and it is predicted to become the $7^{\text {th }}$ leading cause of death by 2030 [1].

The problem of trauma is most acute in sub Saharan Africa, where the proportion of such deaths from trauma is higher than in any other region of the world and where the risk of death from injury is greatest, particularly for men in the age group 15-29 years. Trauma has been described as a 'malignant epidemic' [13]. In Ethiopia, like other low income countries, injuries are common and nearly 19,000 road traffic accidents occurred each year, claiming over 2,500 deaths [14].

Even though, injuries are being predictable and highly preventable, they have been neglected from the global health agenda for many years [1]. Considering the increasing contribution of violence, injury and medical emergencies to the burden of disease, the Ethiopian Health Sector Development Program clearly gives more attention to injuries and violence among other non-communicable diseases. To materialize this, the Ministry of Health has prepared a National Multi Sectoral Strategic Plan in coordination with various sectors. Road traffic injury, fire burn, falls and other work related injuries are priorities in the plan. The plan emphasizes the importance of well-organized emergency medical system in reducing the severity and consequences of injuries and violence. However, there is paucity of comprehensive data on the magnitude and pattern of injury in Ethiopia. Without reliable information, health care planners at all levels are unable to allocate resources so as to achieve the greatest impact in preventing injuries, treating and rehabilitating injured persons. Therefore, this study has an invaluable contribution in feeling such gaps.

\section{Methods and Materials}

\subsection{Study Population and Setting}

Hospital based retrospective cross-sectional study was conducted in Emergency department of Hawassa University Comprehensive and Specialized Hospital (HUCSH), from February, 2015 to June 30, 2015 which is found in Hawassa city, $273 \mathrm{Km}$ far from Addis Ababa. The hospital started giving service in since 2005 and serves for more than 18 million people of the catchment area, from the southern region and the surrounding Oromia zones with more than 400 inpatient beds and outpatient services. All injured adult patients visited emergency department of was included in the study. Those injured patients who were in need of immediate transfers to other hospitals and Chart with any missing information was excluded in from this study. A total of 422 patient cards were included in the study using systematic sampling techniques.

\subsection{Data Collection Tools}

Data was collected using structured check list adopted from WHO Injury surveillance guideline with modification. The checklist contains sociodemographic characteristics of patients and injury related factors. The data was collected from documented patient chart that was taken from registered book in emergency room; surgical ward injured patients and recorded data. The data were collected by trained nurses and it was pretested on $5 \%$ of the total sample size before the actual data collection period. After pretest some modifications were done on the checklist.

\subsection{Data Processing and Analysis}

The collected data were checked for completeness and consistency by supervisors and principal investigator on daily basis. The data were entered using Epi-data version 3.1 and analyzed using SPSS version 20 . The analyzed data were presented using frequencies, percentages, tables, charts and figures.

\subsection{Ethical Considerations}

Ethical clearance was obtained from Hawassa University College of medicine and health sciences, Institutional review board. Permission obtained from the head of the Emergency department and card room of the hospital to conduct the study.

\section{Results}

\subsection{Socio-Demographic Characteristics of Study Population}

During the study period, out the total 345 injured patient charts reviewed in this study; there were $277(80 \%)$ are males and $68(20 \%)$ are females. The most injured age group was 21-30 years which accounts 140 (40.6\%), followed by $12-20$ years $85(24.6 \%)$ and the least injured age group was 50 or more years as shown in table 1 .

Table 1. Demographic data variables of injured patients visited to Hawassa university Comprehensive Specialized hospital emergency department $(n=345)$.

\begin{tabular}{llll}
\hline Variable & Categories & In frequency & In \% \\
\hline \multirow{2}{*}{ Sex } & Male & 277 & 80.3 \\
& Female & 68 & 19.7 \\
& $12-20$ & 85 & 24.6 \\
Age & $21-30$ & 140 & 40.6 \\
& $31-40$ & 59 & 17.1 \\
& $41-50$ & 29 & 8.4 \\
& $>50$ & 32 & 9.3 \\
Occupation & NGO & 26 & 7.5 \\
& Student & 90 & 6 \\
& Farmer & 18 & 26.1 \\
\hline
\end{tabular}




\begin{tabular}{llll}
\hline Variable & Categories & In frequency & In \% \\
\hline & Merchant & 21 & 6.1 \\
& Unemployed & 63 & 18.3 \\
& Unknown & 125 & 36.2 \\
\hline
\end{tabular}

\subsection{Patterns of Injury}

Most pattern of injuries were due to road traffic accidents (RTA) which accounts 186 (53.9\%), followed by fighting 76 (22\%), fall down accident $52(15.1 \%)$ and stub injury 11 $(3.2 \%)$ as described in table 2 .

Table 2. The pattern of injuries visited to adult surgical emergency department at Hawassa university Comprehensive Specialized hospital $(n=345)$.

\begin{tabular}{lll}
\hline Causes of injury & Frequency & Percentage (\%) \\
\hline RTA & 186 & 53.9 \\
Fighting & 76 & 22 \\
Heat & 6 & 1.7 \\
Fall down accident & 52 & 15.1 \\
Stab injury & 11 & 3.2 \\
Gunshot & 5 & 1.4 \\
Machinery & 2 & 6 \\
Other & 7 & 2.0 \\
\hline
\end{tabular}

The majority context of injuries were accidental 216 $(62.6 \%)$ and the next by the quarrel $81(23.5 \%)$ followed by drug related like alcohol accounts $11.3 \%$ as shown in figure 1 .

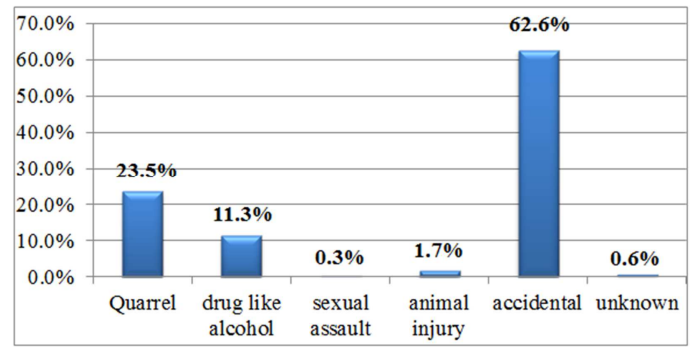

Figure 1. The frequency context of injuries visited to surgical department at Hawassa University Comprehensive Specialized hospital $(n=345)$.

In anatomical position or the injured part of the body; injury to head and neck accounts 181 (52.5\%), followed by injury to extremities $87(25.2 \%)$ as described in figure 2 below.

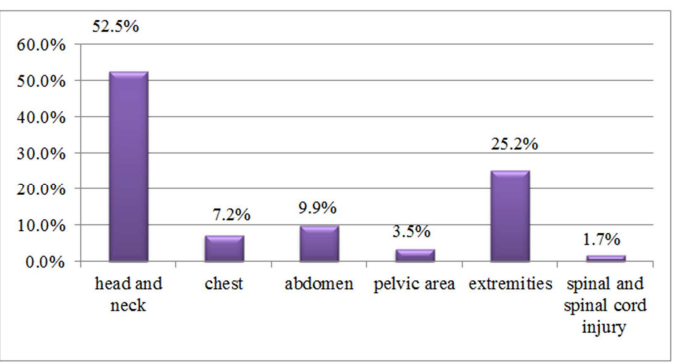

Figure 2. Shows the frequency of the part of the body injured those visited to surgical emergency department of Hawassa University Comprehensive Specialized hospital.

Among the types of injury body fracture accounts 140 $(40.6 \%)$, soft tissue injuries $132(38.3 \%)$, and organ injuries $19(8.3 \%)$ as shown in table 3 .
Table 3. Character/nature of injuries in the body visited to surgical emergency department of Hawassa University Comprehensive Specialized hospital.

\begin{tabular}{lll}
\hline Type of injury & Frequency & Percent \\
\hline Fracture & 140 & 40.6 \\
Dislocation & 16 & 4.6 \\
Soft tissue injury & 132 & 38.3 \\
burn & 7 & 2.0 \\
organ injury & 28 & 8.1 \\
open wound injury & 19 & 5.5 \\
other & 3 & 9 \\
Total & 345 & 100.0 \\
\hline
\end{tabular}

The scene of injury that occur to patients were on transport $139(40.3 \%)$ and at home 54 (15.7) table 4.

Table 4. The scene of injury occurs for the patient visiting to emergency room.

\begin{tabular}{lll}
\hline & Frequency & Percentage \\
\hline Home & 54 & 15.7 \\
Street & 139 & 40.3 \\
Transport & 114 & 33 \\
In industry & 3 & 9 \\
Pedestrian & 20 & 5.8 \\
Farm & 5 & 1.4 \\
Construction site & 10 & 2.9 \\
Total & 345 & 100 \\
\hline
\end{tabular}

Condition of the patient at emergency room $80.6 \%$ were stable, $19.1 \%$ were unstable and $0.3 \%$ were died at arrival to emergency room (table 5). After arriving to emergency department the care given to injured patients was immobilized $43.5 \%$ and resuscitated $39.4 \%$ of injuries, the least treatment was first aid that accounts $13.3 \%$.

Table 5. Condition of the patients visited the emergency department of Hawassa University Comprehensive Specialized Hospital.

\begin{tabular}{lll}
\hline & Frequency & Percentage \\
\hline Stable & 278 & 80.1 \\
Unstable & 66 & 19.1 \\
Died at arrival & 1 & 3 \\
Total & 345 & 100 \\
\hline
\end{tabular}

After 24 hours evaluation the outcome of the patient in emergency room the majority $49 \%$ were sent home and $44.3 \%$ were admitted the ward see below figure 3 .

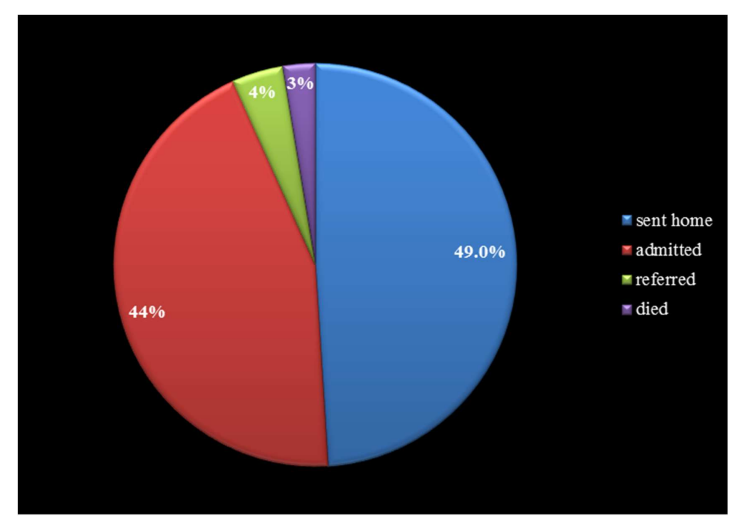

Figure 3. The outcome of the patient in emergency department after evaluation for 24 hours period of time. 


\section{Discussion}

In this study four out of five $(80 \%)$ injured patients were males. This is supported by a study done in Black Lion [15] and Australian study where males are two times highly affected by injuries as compared to females [16]. Because, males may have travelling risk, emotional and risk taking behavior [17]. Moreover, more than $40 \%$ of injured patients were 21-30 years of age, supported by other studies $[15, .17$, 18]. This may be explained by the fact that, this early adulthood is the most active working age group, most people at this time practice self-governing life out of parental supervision, and they may exposed to abuse different substances that increases the risk of such an injuries.

This study also found out that RTA accounts the most common cause of injury contributing nearly $60 \%$ of accidental injuries which is supported by similar studies $[1,5$, 17, 18]. This may be due to lack of well-established road for pedestrians, as the primary victims of RTAs were occurred in the street and on the pedestrians, and no separate pathways for domestic animals in the study area. Also, this might be due to higher migration from rural to urban, those doesn't know the road traffic rule and regulation so they more prone to injury. Furthermore, the impact of RTAs in developing countries like Ethiopia has been noted to be associated with lack of road safety standards and regulation such as the use of protective equipment such as helmets and speed reduction, which can lead to increased severity [19].

The major places for the occurrence of injury were street for $40.3 \%$ cases, which is similar to studies conducted in Amhara region [17], Jimma [20], and Black Lion hospital [15]. Accidental injuries also account nearly two-third $(62.6 \%)$ of the cases as to a study done in Amhara region [17] and Yirgalem [18]. This is because of the fact that accidental or unintentional injuries most commonly related to falling down accidents and road traffic accidents which have highest incidence in this study.

In our study the most frequently affected anatomically body part is head and neck injury followed by injuries of extremities. Similar finding was revealed through the studies conducted in Yirgalem hospital [18], western Nepal [21] and India [22]. Furthermore, this study revealed that fractures and soft tissue injuries were the most common types of injuries encountered, which is supported by previous studies [23].

Almost one-fifth of the injured patients were unstable i.e. they were unconscious or have deranged vital signs during their hospital visit. This might be associated with older age, severe head injury, and hypoxia [15] and severe fluid loss due to bleeding or severe pain on presentation. Hence nearly half of the patients were sent to home after 24 hours by providing the appropriate intervention.

\section{Limitation of the Study}

Finally, with its cross-sectional design, this study could not provide causal associations and further longitudinal researches are required. Second, this study only assessed the descriptive part. This might hinder the associated factors.

\section{Conclusion \& Recommendation}

The cause of injury by road traffic accident was high in young age group so it should include in health education to teach the society to prevent RTA injury and raising public awareness to the consequence of injury. This research is crucial and base line to understand the problems of injury and the policy maker will develop guide lines to prevent the cause of trauma and improving health care service systems in health institutions and society.

\section{Authors' Contributions}

TF has conceived the study and was involved in the study design, reviewed the article, analysis, report writing. MA had drafted the manuscript. All authors read and approved the final manuscript.

\section{Acknowledgements}

The authors appreciate respective study institutions, data collectors and study participants for their cooperation in providing the necessary information.

\section{References}

[1] WHO (World Health Organization). INJURIES and VIOLENCE: THE FACTS. WHO (World Heal Organ. 2014.

[2] Chandran A, Hyder A P-AC. The global burden of unintentional injuries and an agenda for progress. Epidemiol Rev. 2010; 32 (1); 110-20.

[3] Prevention $\mathrm{C}$ for DC and. The Leading Cause of Death Among Persons 1-44. Inj Prev Control. 2013.

[4] Prevention C for DC and. Saving Lives and Protecting People from Violence and Injuries. Inj Cent. 2012.

[5] Prevention C for DC and. Injury Response. Inj Cent. 2011.

[6] Villaveces A, Ph D, Mutter R, Ph D, Owens PL, Ph D, et al. Causes of Injuries Treated in the Emergency Department. $2013 ; 1-8$.

[7] Sethi D et al. Progress in preventing injuries in the WHO European Region. Copenhagen, WHO Reg Off Eur. 2008.

[8] Matthew, E. J., R. Erik, G. and Michelle H. The Prevalence of Injury of Any Type in an Urban Emergency Department Population. J TRAUMA_Inj Infect Crit Care. 2008.

[9] Nordberg E. Injuries in Africa: A review. East Afr Med J. 1994; 7 (6); 339-45.

[10] Zwi A, M. S., Miska B et al. injury surveillance in Zimbabwe : a situation analysis ministry of health \& child welfare. 1993.

[11] World Health Organization. Global status report on road safety 2015. Geneva World Heal Organ. 2015. 
[12] Ogendi JOK1 AJ. Causes of injuries resulting in a visit to the emergency department of a Provincial General Hospital, Nyanza, western Kenya. Afr Health Sci. 2011; 11 (2).

[13] Ethiopia NRSCO. Overview of the Road Safety in Ethiopia. 2008.

[14] Landes M, Venugopal R, Berman S, Heffernan S, Maskalyk J. Epidemiology, clinical characteristics and outcomes of head injured patients in an Ethiopian emergency centre. African $\mathrm{J}$ Emerg Med [Internet]. 2017; 7 (3); 130-4. Available from: http://dx.doi.org/10.1016/j.afjem. 2017. 04. 001.

[15] Hendrie D, Miller TR, Randall S, Brameld K, Moorin RE. Incidence and costs of injury in Western Australia 2012. 2016; Available from: https://ww2.health.wa.gov.au/Reports-andpublications/Incidence-and-costs-of-injury-in-wa

[16] Bashah DT, Dachew BA, Tiruneh BT. Prevalence of injury and associated factors among patients visiting the Emergency Departments of Amhara Regional State Referral Hospitals, Ethiopia : a cross-sectional study. BMC Emerg Med [Internet] 2015; 1-7. Available from: http://dx.doi.org/10.1186/s12873015-0044-3.

[17] Negussie A, Getie A, Manaye E, Tekle T. Prevalence and outcome of injury in patients visiting the emergency
Department of Yirgalem General Hospital, Southern Ethiopia. 2018; 1-5.

[18] WHO (World Health Organization). Global Status Report on Road Safety 2013: Supporting a Decade of Action. 2013.

[19] Woldemichael K BN. Magnitude and Pattern of Injury in Jimma University Specialized Hospital, South West Ethiopia. Ethiop J Heal Sci. 2011; 21 (3); 155-65.

[20] Mishra, B., Sinha, N. D., Sukhla, S. and Sinha A. Epidemiological Study of Road Traffic Accident Cases from Western Nepal. Indian J Community Med. 2010; 30 (115).

[21] Singh, D., Singh, S. P., Kumaran, M. and Goel S. Epidemiology of Road Traffic Accident Deaths in Children in Chandigarh Zone of North West India. Egypt J Forensic Sci. 2015; 6: 255-60.

[22] Singh, R., Singh, H. K., Gupta, S. and Kumar Y. Pattern, Severity and Circumtances of Injuries Sustained in Road Traffic Accidents: A Tertiary Care Hospital-Based Study. Indian J Community Med. 2014; 39 (30).

[23] Nóbrega, L. M., Cavalcante, G. M., Lima, M. M., Madruga, R. C., Ramos-Jorge ML, and d'Avila S. Prevalence of Facial Trauma and Associated Factors in Victims of Road Traffic Accidents. Am J Emerg Med. 2014; 32: 1382-6. 